RESEARCHARTICLE

\title{
Evaluation of a web-based self-compassion intervention to reduce student assessment anxiety
}

\author{
Kirsten McEwan ${ }^{1 *}$, James Elander' and Paul Gilbert ${ }^{2}$ \\ ${ }^{1}$ Centre for Psychological Research, University of Derby, UK \\ ${ }^{2}$ Compassionate Mind Foundation, Derby, UK
}

\begin{abstract}
Assessment anxiety is associated with excessive worry and cognitive disruption which can contribute to academic failure. Compassion-focused interventions have previously been effective in reducing anxiety, stress and depression among the general population. Aims: This study extended this approach to students whose academic achievement is potentially compromised by assessment anxiety, by evaluating a web-based compassionate imagery intervention.
\end{abstract}

Students $(n=48)$ who self-identified as assessment anxious were randomised to practice either compassionate imagery exercises or to a control condition of practicing relaxation exercises. Students completed measures of test anxiety, mastery and performance learning goals, self-compassion, self-criticism/self-reassurance, depression, anxiety and stress, before and after the two-week intervention.

The compassionate imagery exercises improved self-compassion more than the control condition of relaxation exercises did. Both tasks improved students' well being, and reduced assessment anxiety among those with higher baseline assessment anxiety. Webbased compassionate imagery and relaxation may offer cost-effective interventions for reducing assessment anxiety. More research is needed on the influence of selfcompassion on learning processes and academic performance and achievement.

Open Access

Citation: McEwan, K., Elander, J.,Gilbert, P. 2018. Evaluation of a web-based self-compassion intervention to reduce student assessment anxiety. Interdisciplinary Education and Psychology, 2(1):6.

Received: November 09, 2017

Accepted: April 23, 2018

Published: May 04, 2018

Copyright: @ 2018 McEwan et al. This is an open access article distributed under the terms of the Creative Commons Attribution License, which permits unrestricted use, distribution, and reproduction in any medium, provided the original author and source are credited.

Corresponding author: Kirsten McEwan, University of Derby, Kedleston Road, Derby, DE22 1GB, UK E-mail: k.mcewan@derby.ac.uk

\section{Keywords}

Assessment anxiety; compassion; mastery goals; performance goals; relaxation

\section{Introduction}

Mental health problems are increasingly prevalent among students, and anxiety is among the most common type of problem (Royal College of Psychiatrists, 2011). Assessment or test anxiety has been identified by undergraduates (Bishop et al., 1998) and younger students (Childline, 2015) as an important problem for which they seek counselling and is associated with impaired academic performance and achievement (Cassady \& Johnson, 2002; Chapell et al., 2005; Putwain \& Daly, 2013).

Reductions in test anxiety were related to improvements in test performance (Driscoll, 2007), and a meta-analysis showed that reducing test anxiety improved test performance and academic achievement (Hembree, 1988). One key approach to learning that has been associated with assessment anxiety is the adoption of performance rather than mastery goals (Elliot \& McGregor, 2001). Students with performance goals are motivated to defend or enhance their self-worth, and make judgements about their ability based on success or failure and comparisons with others, whereas those with mastery goals set their own standards for learning, view learning as an opportunity for growth and development, and view setbacks and mistakes as part of the learning process (Ames, 1992; Ames \& Archer, 1988; Elliot \& McGregor, 2001). 
A meta-analysis indicated that the most effective test anxiety reduction interventions were combinations of cognitive or behavioural and skills-based interventions, delivered both individually and in group sessions (Ergene, 2003), but better evidence is needed about the relative efficacy of interventions for test anxiety among university students (Huntley et al., 2016). Other interventions focused on increasing relaxation, mindfulness, reappraisal and attention. For example, a relaxation training programme led to significant reductions in test anxiety among third grade students (Larson, et al., 2010), and deep breathing training led to greater feelings of relaxation and confidence among premedical students (Paul et al., 2007). Mindfulness interventions improved student behaviour and educational achievement (Black \&Fernando, 2014; Klatt et al., 2013; Sharifiniya \& Golmohammadi, 2014), and reduced stress and depression among primary and secondary students (Kuyken et al., 2013; Wisner, 2014). Breathing exercises encouraging mindful attention led to higher calmness ratings and better performance on a maths task among adults with maths anxiety (Brunye et al., 2013). An intervention using self-talk to reappraise pre-performance anxiety as excitement helped individuals prepare for performance-based tasks and improve their performance (WoodBrooks, 2013). Imagery rescripting led to reductions in test anxiety that were maintained for 6 months (Reiss et al., 2016), and an attentional training intervention helped students feel less stressed about an examination (Dandeneau et al., 2007). However, to our knowledge no studies have evaluated compassion-focused or online interventions for assessment anxiety.

Self-compassion, which involves being kind to oneself about instances of failure, and perceiving negative experiences as part of the larger human experience, may also be a useful focus for interventions for assessment anxiety. Indeed, some clinicians have suggested compassion interventions in schools could improve mental wellbeing in general (Welford \& Langmead, 2015). Self-compassionate individuals are motivated to achieve but their goals are driven by the desire to maximise potential and wellbeing rather than bolster self-image (Neff, 2003a).Self-compassion has been associated with adopting academic mastery rather than performance goals (Akin, 2008; Williams et al., 2008). In two studies, self-compassion was positively associated with mastery goals and negatively associated with performance goals, and was also associated with less fear of failure, fewer avoidance-related strategies, and greater perceived confidence, self-determination and emotion-focused coping strategies (Neff et al. 2005). Self-compassion was also associated with greater self-efficacy and satisfaction with university, and less academic worry and procrastination.

Shepherd and Cardon (2009) proposed that self-compassion allows individuals to assess setbacks and failures whilst remaining objective and divorced from evaluations of self-worth, so they can explore failures with curiosity and openness and learn from them. A key aim of selfcompassion interventions is to stimulate positive emotions and tone down self-criticism and negative emotions. For example, imagery exercises with a kindness or compassionate focus (i.e. imagining giving or receiving kindness and compassion) led to increased positive emotions, mindfulness, and feelings of purpose in life (Fredrickson et al., 2008). Selfcompassion interventions have also led to participants taking more responsibility for their role in negative events (Leary et al., 2007), spending more time studying for a difficult test following an initial failure, and being more motivated to change personal weakness (Breines \& Chen, 2012). Smeets et al. (2014) delivered a three-week self-compassion group intervention among female students. The intervention involved psychologist-led group sessions with homework tasks comprising compassionate letter writing. The compassion intervention led to greater improvements in self-compassion, mindfulness and optimism compared with a control condition of time management skills. However, these studies did not explore academic or assessment anxiety.

Online interventions have been effective in reducing mental health difficulties among university students (Musiat et al., 2014), and their anonymous, flexible nature is consistent with student preferences for help-seeking (Chew-Graham et al., 2003). Interventions delivered online are also generally extremely cost-effective (Hedman et al., 2011, 2014). Compassionate imagery interventions have often been more effective among those with greater psychological distress at baseline (Kelly et al., 2010; McEwan \& Gilbert, 2016; Shapira \& Mongrain, 2010), and the same is true for online interventions among university students (Musiat et al., 2014).

In the present study we therefore evaluated a web-based self-compassion intervention by comparison with a stringent control condition of a web-based relaxation intervention for 
university students with assessment anxiety. The self-compassion intervention included compassionate imagery exercises that previously led to increased wellbeing and reduced self-criticism, anxiety and stress among university staff and students (McEwan \& Gilbert, 2016). The relaxation intervention involved standard relaxation exercises and imagery exercises that were available from the University student support services at the time of the study, thus acting as a stringent control of 'treatment as usual'. We hypothesised that both the intervention and control would reduce assessment anxiety and other measures of psychological wellbeing, but that the self-compassion intervention would have a greater effect, especially for students with high assessment anxiety at baseline.

\section{Materials and Methods}

\section{Participants}

Participants were 48 university students who identified themselves as affected by assessment-related anxiety. There were 43 females and 5 males ( 2 males in the compassion condition and 3 males in the relaxation condition). Ages ranged from 18 to 58 years $(M=33.81$, $S D=11.73)$. There were $21(43.8 \%)$ in their first year of study, $12(25 \%)$ in their second year, 9 $(18.8 \%)$ in their third year, and $6(12.5 \%)$ in their fourth year. The study was advertised through student email lists and posters/flyers around the University (especially distributed in the student wellbeing service waiting room area).

\section{Measures}

The primary outcome measure was the Westside Test Anxiety Scale (Driscoll, 2007), a selfreport measure with 10 items, each rated on 1 ('not at all or never true') to 5 ('extremely or always true') scales. Example items include: 'During important exams, I think that I am doing awful or that I may fail.' Scores are computed as the mean across all 10 items and interpreted as: 1 to $1.9=$ low, 2 to $2.4=$ normal, 2.5 to $2.9=$ high normal, 3 to $3.4=$ high moderate, 3.5 to 3.9 = high, 4 to $5=$ extremely high (Driscoll, 2007). Validity has been shown in some small samples. The scale has shown a moderate positive correlation with the Cognitive Test Anxiety Scale (Cassidy \& Johnson, 2002) and a reliability score of $\alpha=0.88$ (Larson et al., 2010).

Secondary outcome measures were: the 18-item Goal Orientation Scale, which measures mastery and performance learning goal orientation, reliability for this scale ranged from $\alpha=0.70-0.80$ across multiple samples, example items include: 'I like school work that l'll learn from, even if I make a lot of mistakes'(Midgley et al., 2000); the 26-item Self-compassion Scale, which measures self-compassion and self-coldness, reliability for this scale was $\alpha=0.91$, an example item is: 'I try to be understanding and patient towards those aspects of my personality I don't like'(Neff, 2003b), the 22-item Forms of Self-criticism/Reassurance Scale, which measures inadequate self-criticism $(\alpha=0.90)$, hated self-criticism $(\alpha=0.86)$ and reassured self ( $\alpha=0.86)$, example items include: "I am easily disappointed with myself"(Gilbert et al., 2004), and the 21-item Depression ( $\alpha=0.94)$, Anxiety ( $\alpha=0.87)$ and Stress $(\alpha=0.91)$ Scale, example items include: "I couldn't seem to experience any positive feelings at all"(Lovibond \& Lovibond, 1995).

Participants also completed a brief weekly diary during the intervention, with measures of 1) how often they practiced the exercises, 2) how easy they found them, 3) how hard participants tried with the exercises, 4) how emotionally moved they were by them, and 5) how much resistance they experienced to the imagery. These ratings were made on 10-point scales from 0 to 10 . The diary measures also invited direct qualitative feedback about participants' experience of the exercises, and their feelings of anxiety about a specific upcoming assessment.

To our knowledge, few intervention studies for assessment anxiety have included follow-up measures (see Dandeneau et al., 2007, and Paul et al., 2007, for exceptions), and few have looked at actual exam/assessment experience or performance. Participants therefore also completed a brief three item follow-up measure which asked 1) how much impact the intervention had on their experience of the assessment 2) their actual performance in the assessment (rated 0-4; 'no impact at all' to 'high impact'), and 3) how their recent assessment experience compared with previous ones (rated 0-4; 'much worse' to 'much better'). They were then given room to provide written qualitative feedback on how the intervention affected their assessment experience. 


\section{Procedure and interventions}

Participants were recruited through electronic dissemination of a message inviting students affected by assessment-related anxiety to participate. Students who responded and completed baseline measures were randomised to compassionate imagery exercises $(n=$ 23 ), or relaxation exercises $(n=25)$. For both groups, online audio downloads were provided containing guided instructions. The compassionate imagery exercises began with soothingrhythm breathing followed by two imagery exercises which involved imagining oneself as a compassionate person, and imagining receiving compassion and care from another being or person. The relaxation exercises were the same as those routinely offered by the Student Wellbeing Service website at the time of the study, and involved slow breathing, muscle relaxation, and imagining or remembering a positive, soothing and relaxing experience such as a natural environment.

Participants were encouraged to practice the imagery exercises for a minimum of five minutes per day over two weeks and were sent daily email reminders with prompts about how to practice the imagery. The questionnaire measures were completed at baseline and after two weeks of practising the exercises. Diary measures were completed at the end of each week. Participants were then re-contacted following the University assessment period three months later to complete the follow-up measures.

\section{Results}

Participants' test anxiety scores indicated that 3(6.3\%) had low, $9(18.8 \%)$ normal, $12(25 \%)$ high normal, 7 (14.6\%) moderately high, 8 (16.7\%) high, and $9(18.8 \%)$ extremely high-test anxiety. When asked about their primary source of assessment anxiety, there were 24 participants (50\%) who were anxious about examinations, $11(22.9 \%)$ who were anxious about course work, $11(22.9 \%)$ anxious about presentations, one (2.1\%) about a viva voce examination, and one (2.1\%) about an 'other assessment'.

Data were analysed using IBM SPSS version 22 (IBM). Variables were assessed for normality using scatterplots, skewness and kurtosis. Hated self-criticism was skewed and kurtotic which is typical of a non-clinical population (Gilbert et al., 2011). This variable was log transformed for further analysis. In the final dataset for analysis skewness ranged from 0.36 to 1.47 , kurtosis ranged from -0.19 to 2.87 . There were no significant differences in age or any of the questionnaire measures at baseline between randomized groups ( $t$ values $(d f=46)$ ranged from 0.012 to 1.685 , with $p>0.05$ in every case).

Table 1. Means and standard deviations for all measures featuring all participants and highrisk participants assigned to the compassion or relaxation conditions

\begin{tabular}{|c|c|c|c|c|c|}
\hline Measure & Group & Before & After & $\begin{array}{l}\text { High risk } \\
\text { before }\end{array}$ & High risk after \\
\hline \multirow[t]{2}{*}{ Test Anxiety } & Compassion & $29.35(8.48)$ & $29.22(9.12)$ & $34.20(6.13)$ & $33.00(7.97)$ \\
\hline & Relaxation & $31.80(7.78)$ & $29.48(7.69)$ & $33.90(6.56)$ & $31.00(7.46)$ \\
\hline \multirow[t]{2}{*}{ Mastery goals } & Compassion & $25.26(3.77)$ & 24.09 (3.91) & $25.73(4.10)$ & $24.20(3.97)$ \\
\hline & Relaxation & $25.00(3.48)$ & $25.48(2.89)$ & $24.43(3.41)$ & $25.19(2.64)$ \\
\hline Performance & Compassion & $15.96(5.17)$ & $14.61(5.11)$ & $13.80(4.23)$ & $13.47(5.32)$ \\
\hline goals & Relaxation & $14.16(5.62)$ & $14.28(6.54)$ & $14.43(5.53)$ & $14.33(6.29)$ \\
\hline \multirow[t]{2}{*}{ Self-compassion } & Compassion & $17.04(5.03)$ & $19.39(5.48)$ & $15.53(4.47)$ & $17.49(9.14)$ \\
\hline & Relaxation & $19.20(3.81)$ & $19.40(4.25)$ & 18.95 (3.34) & $19.29(3.96)$ \\
\hline \multirow[t]{2}{*}{ Self-coldness } & Compassion & $20.30(4.56)$ & $17.65(6.01)$ & $21.27(4.50)$ & $18.87(6.15)$ \\
\hline & Relaxation & $19.64(4.91)$ & $17.04(5.85)$ & $20.76(3.75)$ & $17.67(5.37)$ \\
\hline \multirow[t]{2}{*}{ Inadequate self } & Compassion & $18.65(8.86)$ & $16.04(10.11)$ & $21.07(8.28)$ & $17.87(10.49)$ \\
\hline & Relaxation & $18.68(7.20)$ & $15.60(7.81)$ & $20.00(6.31)$ & $16.14(7.50)$ \\
\hline \multirow[t]{2}{*}{ Hated self } & Compassion & $3.22(4.50)$ & $2.96(4.95)$ & $3.53(4.78)$ & $3.67(5.72)$ \\
\hline & Relaxation & $2.80(3.61)$ & $3.08(3.40)$ & $2.95(3.88)$ & $3.19(3.41)$ \\
\hline \multirow[t]{2}{*}{ Reassured self } & Compassion & $17.48(6.56)$ & $19.70(7.91)$ & $15.60(6.75)$ & $16.80(7.06)$ \\
\hline & Relaxation & $20.44(5.61)$ & $21.04(6.28)$ & $19.52(5.14)$ & $20.05(5.55)$ \\
\hline \multirow[t]{2}{*}{ Depression } & Compassion & $4.35(4.54)$ & $2.83(3.30)$ & $4.93(4.82)$ & 3.27 (3.39) \\
\hline & Relaxation & $3.96(3.02)$ & $3.36(3.63)$ & $4.33(3.15)$ & $3.19(3.20)$ \\
\hline \multirow[t]{2}{*}{ Anxiety } & Compassion & $5.26(5.60)$ & $3.35(4.42)$ & $6.27(6.20)$ & $4.20(5.27)$ \\
\hline & Relaxation & $3.88(4.09)$ & $3.44(3.84)$ & $4.33(4.31)$ & 3.33 (3.99) \\
\hline \multirow[t]{2}{*}{ Stress } & Compassion & $8.70(5.11)$ & $6.09(4.91)$ & $9.20(5.02)$ & $6.87(4.98)$ \\
\hline & Relaxation & $7.48(4.75)$ & $6.28(4.53)$ & $7.90(4.68)$ & $6.52(4.49)$ \\
\hline
\end{tabular}




\section{Effectiveness of interventions}

A mixed measure repeated MANOVA with group (compassionate imagery vs. relaxation imagery) as the between-subjects variable and time (baseline vs. post-intervention) as the within-subject factor was conducted. The multivariate tests showed a significant effect of time $\left[F(11,36)=3.93, p=0.001, \eta_{p}{ }^{2}=0.546\right]$ but no significant interaction $[F(11,36)=1.96, p=$ $\left.0.063, \eta_{\mathrm{p}}{ }^{2}=0.375\right]$, or significant effect of group $\left[\mathrm{F}(11,36)=0.82, p=0.617, \eta_{\mathrm{p}}{ }^{2}=0.201\right]$. The univariate tests showed significant changes over time in self-compassion $[F(11,46)=9.69, p$ $\left.=0.003, \eta_{p}{ }^{2}=0.174\right]$, self-coldness $\left[F(11,46)=23.13, p<0.001, \eta_{p}{ }^{2}=0.335\right]$, inadequate selfcriticism $\left[\mathrm{F}(11,46)=16.43, p<.001, \eta_{\mathrm{p}}{ }^{2}=.263\right]$, self-reassurance $[\mathrm{F}(11,46)=6.71, p=0.013$, $\left.\eta_{p}{ }^{2}=0.127\right]$, anxiety $\left[F(11,46)=5.98, p=0.018, \eta_{p}{ }^{2}=0.115\right]$ and stress $[F(11,46)=8.40, p=$ $\left.0.006, \eta_{p}{ }^{2}=0.154\right]$, with particularly high effect sizes for self-coldness and inadequate self criticism. Mean values are shown in Table 1. Self-compassion and self-reassurance increased, and self-coldness, inadequate self-criticism, anxiety and stress decreased after engaging with the interventions. There were no significant changes in test anxiety, mastery or performance goal orientation, hated self-criticism or depression. We do note from Table $1 \mathrm{a}$ non-significant trend for those in the relaxation group to have higher baseline compassion scores and at post-intervention compassion scores for the self-compassion group increased to the level already prevalent in the relaxation group at baseline. We conducted an additional MANOVA checking for the effect of self-compassion scores at baseline as a covariate and found no significant interaction effect $(p=0.139)$.

The univariate tests for the time $\mathrm{x}$ group interaction showed significant effects on mastery goal orientation $\left[\mathrm{F}(1,46)=4.22, p=0.046, \mathrm{n}_{\mathrm{p}}{ }^{2}=0.084\right]$ and self-compassion $[\mathrm{F}(1,46)=6.89, p$ $\left.=0.012, \eta_{p}{ }^{2}=0.130\right]$. Figure 1 shows that mastery goal orientation was increased by the relaxation intervention but decreased by the compassion intervention. Figure 2 shows that self-compassion was increased to a far greater extent by the compassion intervention than by the relaxation intervention.

We then restricted the analysis to the 34 participants with higher assessment anxiety at baseline (mean score $>=3.00$ ). The multivariate tests showed significant effects of time $[F(11$, $\left.22)=4.11, p=0.002, \eta_{p}{ }^{2}=0.673\right]$, but not group $\left[F(11,22)=1.85, p=0.106, \eta_{p}{ }^{2}=0.481\right]$ or time $x$ group $\left[F(11,22)=1.22, p=0.331, \eta_{p}{ }^{2}=0.379\right]$. The univariate tests revealed significant effects of time on test anxiety $\left[F(1,32)=5.82, p=0.022, \eta_{p}{ }^{2}=0.154\right]$, as well as self-compassion $\left[F(1,32)=4.57, p=0.040, \eta_{p}{ }^{2}=0.125\right]$, inadequate self-criticism $\left[F(1,32)=24.34, p<.001, \eta_{p}{ }^{2}=\right.$ $0.432]$, depression $\left[\mathrm{F}(1,32)=4.36, p=0.045, \eta_{\mathrm{p}}{ }^{2}=0.120\right]$, anxiety $[\mathrm{F}(1,32)=9.85, p=0.004$, $\left.\eta_{\mathrm{p}}{ }^{2}=0.235\right]$, and stress $\left[\mathrm{F}(1,32)=5.02, p=0.032, \eta_{\mathrm{p}}{ }^{2}=0.136\right]$, with particularly strong effect sizes for inadequate self criticism and anxiety. Self-compassion increased, and test anxiety, inadequate self-criticism, depression, anxiety and stress scores decreased (descriptives can be found in Table 1).

Figure 1. Changes in mastery goal orientation by group

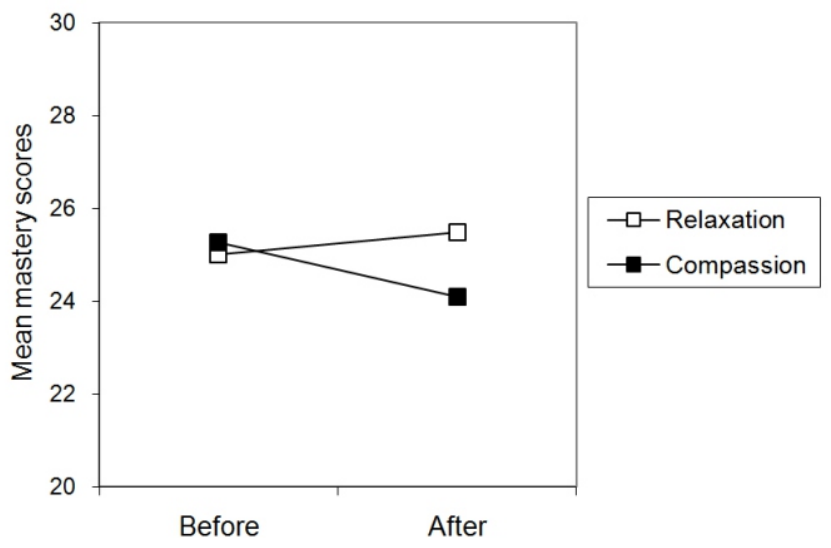


Figure 2. Changes in self-compassion by group

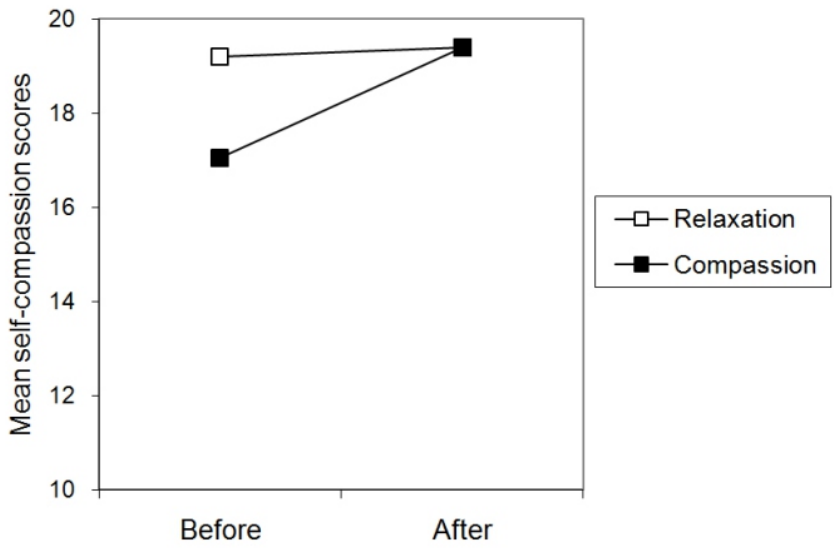

\section{Diary measures}

In the compassion group, diary data showed that 9 participants practiced only the compassion exercises, 8 practiced only the soothing rhythm breathing, and six practiced a mix of both exercises. Seventeen participants practiced every day and 6 practiced every other day. The mean ratings showed that after two weeks participants found it reasonably easy to evoke compassionate emotions $(M=6.26, S D=2.21)$, tried reasonably hard with the imagery $(M=5.84, S D=2.63)$, were partly emotionally moved by the imagery $(M=5.58, S D=2.91)$, and showed a little resistance to the imagery $(M=3.47, S D=1.98)$. Frequently occurring qualitative comments were that the exercises provided a positive, enjoyable, helpful or calming experience (10 participants). Some participants experienced increased selfcompassion and compassion for others, or reduced anxiety. There were also some negative comments, including that it was hard to focus on the imagery (4 participants). Two participants found it hard to imagine compassion for themselves, one person found it hard to imagine someone else being compassionate to them, one felt embarrassed, one felt less enthused and spontaneous with their imagery by the second week, one felt it was not enough during frustrating scenarios, and one person felt that a longer practice period with briefer instructions would be helpful.

In the relaxation group, 20 participants practiced daily and 5 practiced every other day. The mean ratings indicated that by the end of the two weeks participants showed good ease of feeling relaxation $(M=7.00, S D=2.30)$, they tried hard with the imagery $(M=7.71, S D=$ $1.65)$, and they showed little resistance to the imagery $(M=4.10, S D=2.61)$. Frequently occurring qualitative comments were that the relaxation exercises were enjoyable $(n=9)$, and a good time out during the day $(n=4)$ and helped participants to feel less stressed $(n=11)$, less irritable $(n=2)$ and better able to sleep $(n=3)$. However, some also reported feeling more relaxed at first but that this did not last, particularly in difficult scenarios $(n=4)$. One participant found the exercise too short, one found the exercise was too rushed so they did not feel relaxed, one found it hard to imagine a place of nature, one found it was not as effective during times of stress, and one felt too pressured to engage properly.

\section{Follow-up analysis}

Given that only 15 participants in the compassion condition specifically used the compassionate imagery task and the remaining used soothing rhythm breathing, we re-ran the MANOVA including only those 15 participants who used compassionate imagery (see Table 2 for descriptives). The multivariate tests showed a significant effect of time $[F(11,27)=$ $\left.6.01, p=0.000, \eta_{p}^{2}=0.710\right]$ and a significant interaction $\left[\mathrm{F}(11,27)=4.36, p=0.001, \eta_{p}{ }^{2}=\right.$ $0.640]$, but no significant effect of group $\left[F(11,27)=0.72, p=0.712, \eta_{p}{ }^{2}=0.226\right]$. The univariate tests showed significant changes over time in self-compassion $[F(11,27)=26.57, p$ $\left.=0.000, \eta_{p}{ }^{2}=0.418\right]$; self-coldness $\left[F(11,27)=21.33, p=0.000, \eta_{p}{ }^{2}=0.366\right]$; inadequate self $[F$ $\left.(11,27)=14.55, p=0.001, \eta_{p}{ }^{2}=0.282\right]$; self-reassurance $\left[F(11,27)=9.65, p=0.004, \eta_{p}{ }^{2}=\right.$ $0.207]$; anxiety $\left[\mathrm{F}(11,27)=7.75, p=0.008, \mathrm{\eta}_{\mathrm{p}}{ }^{2}=0.173\right]$ and stress $[\mathrm{F}(11,27)=8.30, p=0.007$, $\left.\eta_{p}{ }^{2}=0.183\right]$. We also repeated this analysis for the participants who scored highly on test anxiety at baseline. This resulted in a significant main effect of time $[F(11,17)=4.80, p=$ $\left.0.002, \eta_{p}^{2}=0.756\right]$ but no significant interaction $\left[F(11,17)=2.38, p=0.053, \eta_{p}{ }^{2}=0.606\right]$ or group effects $\left[F(11,17)=0.871, p=0.582, \eta_{p}^{2}=0.360\right]$. The univariate tests showed significant 
changes over time in self-compassion $\left[\mathrm{F}(11,17)=14.08, p=0.001, \mathrm{n}_{\mathrm{p}}{ }^{2}=0.343\right.$ ]; self-coldness $\left[\mathrm{F}(11,17)=19.85, p=0.000, \eta_{p}{ }^{2}=0.424\right]$; inadequate self $\left[\mathrm{F}(11,17)=14.96, p=0.001, \eta_{p}{ }^{2}=\right.$ $0.357]$; depression $\left[\mathrm{F}(11,17)=4.81, p=0.037, \mathrm{n}_{\mathrm{p}}{ }^{2}=0.151\right]$; anxiety $[\mathrm{F}(11,17)=9.18, p=$ $\left.0.005, \eta_{p}^{2}=0.254\right]$ and stress $\left[F(11,17)=5.90, p=0.022, \eta_{p}^{2}=0.179\right]$. In both of these analyses, mean scores indicate that the compassion condition was more effective at improving scores across these variables and this was shown to be significant in a $t$ test comparing change scores on the self-compassion scale $(t=4.68,(37), p=0.000)$, and selfreassurance scale $(t=2.13,(37), p=0.040)$ with self-compassion and self-reassurance significantly improving more in the compassion condition than the relaxation condition and a $t$ test including participants scoring higher in test anxiety showing self-compassion significantly improving more in the compassion condition $(t=3.17,(27), p=0.004)$.

Table 2. Means and standard deviations for all measures featuring participants who specifically practiced compassion vs those who practiced soothing rhythm breathing

\begin{tabular}{|c|c|c|c|c|c|}
\hline Measure & Group & Before & After & $\begin{array}{l}\text { High risk } \\
\text { before }\end{array}$ & High risk after \\
\hline \multirow[t]{2}{*}{ Test Anxiety } & Compassion & $29.20(8.06)$ & $27.80(7.83)$ & $35.75(3.62)$ & $30.88(7.04)$ \\
\hline & Breathing & $29.63(9.81)$ & $31.88(11.24)$ & $39.67(7.51)$ & $41.00(7.00)$ \\
\hline \multirow[t]{2}{*}{ Mastery goals } & Compassion & $25.47(3.66)$ & $24.60(3.16)$ & $26.13(4.12)$ & $24.13(3.44)$ \\
\hline & Breathing & $22.88(4.19)$ & $23.15(5.14)$ & $25.67(3.06)$ & $22.00(2.65)$ \\
\hline Performance & Compassion & $16.93(4.38)$ & $14.87(5.25)$ & $15.63(3.46)$ & $14.75(5.57)$ \\
\hline goals & Breathing & $14.13(6.41)$ & $14.13(5.17)$ & $11.00(6.00)$ & $13.00(4.58)$ \\
\hline \multirow[t]{2}{*}{ Self-compassion } & Compassion & $16.47(4.69)$ & $20.40(5.10)$ & $15.63(5.48)$ & $19.38(5.60)$ \\
\hline & Breathing & $18.13(5.79)$ & $17.50(6.02)$ & $17.00(3.46)$ & $16.00(4.58)$ \\
\hline \multirow[t]{2}{*}{ Self-coldness } & Compassion & $19.93(5.31)$ & $16.67(6.14)$ & $21.63(5.58)$ & $18.00(6.52)$ \\
\hline & Breathing & $21.00(2.83)$ & 19.50 (5.68) & $21.00(4.36)$ & 22.67 (7.09) \\
\hline \multirow[t]{2}{*}{ Inadequate self } & Compassion & $18.07(8.79)$ & $14.53(9.53)$ & $19.50(9.49)$ & $15.25(10.11)$ \\
\hline & Breathing & $19.75(9.50)$ & $18.88(11.21)$ & $22.67(9.02)$ & $21.67(13.05)$ \\
\hline \multirow[t]{2}{*}{ Hated self } & Compassion & $3.47(4.75)$ & $2.87(4.67)$ & $2.88(5.19)$ & $6.23(5.50)$ \\
\hline & Breathing & $2.75(4.27)$ & $3.13(5.77)$ & $5.33(6.66)$ & $6.33(9.29)$ \\
\hline \multirow[t]{2}{*}{ Reassured self } & Compassion & $16.87(6.65)$ & $20.07(7.78)$ & $14.50(7.39)$ & $18.38(7.25)$ \\
\hline & Breathing & $18.63(6.67)$ & $19.00(8.65)$ & $13.00(6.56)$ & 14.00 (8.89) \\
\hline \multirow[t]{2}{*}{ Depression } & Compassion & $5.20(5.14)$ & $2.80(3.30)$ & $5.88(6.29)$ & $2.88(3.64)$ \\
\hline & Breathing & $2.75(2.71)$ & $2.88(3.52)$ & $5.00(3.00)$ & $5.33(3.06)$ \\
\hline \multirow[t]{2}{*}{ Anxiety } & Compassion & $6.13(5.85)$ & $3.07(3.94)$ & $7.00(6.93)$ & $3.38(4.78)$ \\
\hline & Breathing & $3.63(5.04)$ & $3.88(5.46)$ & $4.33(5.13)$ & $4.33(5.86)$ \\
\hline \multirow[t]{2}{*}{ Stress } & Compassion & $9.13(5.03)$ & $5.73(4.95)$ & $9.75(4.80)$ & $6.00(4.99)$ \\
\hline & Breathing & $7.88(5.81)$ & $6.75(5.09)$ & $6.33(3.51)$ & $8.67(4.93)$ \\
\hline
\end{tabular}

There were 25 participants (13 in the compassion group, 12 in the relaxation group) who provided follow-up data in the one-month period after University assessment. In the compassion group, participants rated the compassionate imagery as not having a very large impact on assessment experience $(M=0.77, S D=1.01)$ and as having little impact on their actual performance $(M=0.69, S D=0.85)$. In comparison with previous assessment experiences they rated their current experience as being similar to previous experiences $(M=2.15, S D=0.99)$. The qualitative comments included finding the imagery helped in feeling calmer in the lead up and during the exam and enabled better concentration $(n=5)$. One participant commented that although they felt calmer in the lead-up, they still felt overwhelmed with anxiety on the day.

Responses were similar for the relaxation group. Participants rated relaxation as having a small to moderate impact on assessment experience $(M=1.83, S D=0.83)$ with similar ratings for the effect on their actual performance $(M=1.75, S D=1.14)$. In comparison with previous assessment experiences they rated the current experience as similar to, or slightly better than, previous experiences $(M=2.83, S D=1.12)$. Qualitative comments included feeling calmer $(n=7)$, and having better sleep $(n=2)$, better concentration $(n=4)$, and procrastinating less $(n=2)$. 


\section{Discussion}

The study evaluated a web-based intervention involving compassionate imagery and breathing exercises, compared with one involving relaxation exercises. All the participants self-identified as assessment anxious, and $71 \%$ (34/48) had higher than normal test anxiety scores at baseline. The fact that not all the sample had above normal test anxiety scores shows that even students with low or normal levels of assessment anxiety may experience feelings of worry or anticipation that they interpret as assessment-related anxiety.

There were improvements across both groups, with increases in self-compassion and selfreassurance, and decreases in self-coldness, self-criticism, depression and stress. The strongest effect sizes were for self-coldness and inadequate self criticism, which fits with the aims of Compassion-focused interventions as a way of reducing self-criticism (Gilbert et al., 2004). For assessment anxiety however, there were significant reductions only among those with high baseline assessment anxiety. These effects were strongest for inadequate self criticism and anxiety. This is consistent with previous research showing that those at higher risk (Musiat et al., 2014) or with greater psychological distress can benefit most from interventions (Kelly et al., 2010; McEwan \& Gilbert, 2016; Shapira \& Mongrain, 2010). As the tasks included imagery that was not specifically related to academic matters, they appear to have affected general outcome variables more so than academic variables (such as test anxiety).

The group $x$ time interactions showed that the compassionate imagery intervention increased participants' self-compassion significantly more than the relaxation imagery intervention. This shows that the compassionate imagery had a specific differential effect on exactly the type of outcome to be expected, supporting the validity of the intervention.

The interaction effects also showed that the relaxation intervention increased mastery goals whereas the compassion intervention reduced them. This was not expected, but it is possible that any changes in learning and studying that resulted from an intervention like this would take longer than two weeks. In previous research, self-compassion was not related to academic performance but was related to the motivational patterns underlying academic performance (Neff et al., 2005). Perhaps interventions like those involving compassionate imagery first need to influence self-compassion, and the changes in self-compassion then lead to changes in factors like academic goal orientation.

The quantitative findings were consistent with the evidence from the diary and follow-up measures, which showed that although the interventions influenced participants' mood and wellbeing in a positive way, they had only a small to moderate impact on their experience of assessment. It is unclear why students did not feel the interventions impacted on their actual assessment experience. One participant commented at follow-up that although the exercises helped in the lead up to an exam, they were still overwhelmed by anxiety on the day. More research is needed on how psychological interventions that change mood and self-appraisal processes can also affect academic learning styles and behaviours, and how those changes are translated into reduced anxiety associated with specific assessments, and improved academic performance and achievement. Interestingly, the follow-up data indicated that the relaxation exercises were rated more highly than the compassion exercises. The relaxation exercises involved slow breathing, muscle relaxation, and imagining or remembering a positive experience such as a natural environment, and this combination of task elements may have led to greater perceived effectiveness.

A limitation in this study was lack of representation from male participants, with only 5 males in the sample. The results cannot therefore be generalised to male samples. The study used randomisation, but the sample size was modest and relatively unselected, and the period over which change was assessed was relatively short. The follow-up was limited by attrition, and there were no measures of actual performance or achievement. Not all of those taking part implemented the interventions exactly as instructed, and not all of the participants found the exercises easy to complete. Whilst the compassionate imagery resulted in improvements in general well-being measures, it did not lead to changes in learning goal orientation or assessment-specific anxiety. This could be due to these factors changing over a longer period of time following an increase in self-compassion. Our follow-up did not measure goal orientation or assessment anxiety but focused instead on the exam experience. Future research could provide a more comprehensive range of measures to assess whether there 
are longer-term impacts on learning style and academic anxiety.

Similarities between the two types of task may also have reduced the power of the study to reveal differential effects. The compassionate imagery featured soothing breathing which is similar to the slowed-breathing exercises in the relaxation intervention. This was therefore quite a conservative test of the specific effect of compassionate imagery compared with more generic relaxation imagery as a control. When we re-ran the analyses including only participants in the compassion condition who had practiced the compassion tasks (rather than just the soothing rhythm breathing) we found that compassion scores and self-reassurance scores improved significantly more in the compassion condition compared with the control condition. A study with a larger sample meeting more formal criteria for assessment anxiety, with a longer follow-up including performance and achievement, and comparing compassionate imagery exercise with a less similar intervention, perhaps including a nointervention control group, might be more likely to show a greater intervention impact.

\section{Conclusion}

To conclude, participants found both compassion and relaxation imagery exercises helpful, enjoyable and anxiety alleviating. They increased self-compassion and self-reassurance, and decreased self-criticism, anxiety and stress, and reduced test anxiety among participants with high baseline test anxiety. The compassionate imagery intervention had a greater impact on self-compassion, but it was the relaxation imagery exercises that improved academic mastery goal orientation. More research is needed on ways that interventions like this impact on academic learning and achievement, and how they should be delivered to maximise the benefits for student wellbeing, learning and achievement.

\section{Acknowledgements}

The research was supported by a grant from the Research for Learning and Teaching Fund (RLTF). We are grateful to all the students who took part, and to the University Student Wellbeing Service for their cooperation with recruiting participants, supplying the relaxation audio and administering the study. 


\section{References}

Akın, A. (2008). Self-compassion and achievement goals: A structural equation modelling approach. Journal of Educational Research, 31, 1-15.

Ames, C. (1992). Classrooms: Goals, structures, and student motivation. Journal of Educational Psychology, 84, 261-271.

Ames, C., \& Archer, J. (1988). Achievement goals in the classroom: Students' learning strategies and motivation processes. Journal of Educational Psychology, 80, 260-267.

Bishop, J.B., Bauer, K.W. \& Becker, E.T. (1998). A survey of counselling needs of male and female college students. Journal of College Student Development, 39, 205-210.

Black, D. S. \& Fernando, R. (2014). Mindfulness training and classroom behavior among lower-income and ethnic minority elementary school children. Journal of Child and Family Studies. 23, 1242-1246. DOI 10.1007/s10826-013-9784-4.

Breines, J.G. \& Chen, S. (2012). Self-Compassion Increases Self-Improvement Motivation. Personality and Social Psychology Bulletin, 1-11. DOI: 10.1177/0146167212445599

Brunyé, T.T., Mahoney, C.R., Giles, G.E., Rapp, D.N., Taylor, H.A., \& Kanarek, R.B. (2013). Learning to relax: Evaluating four brief interventions for overcoming the negative emotions accompanying math anxiety. Learning and Individual Differences, 27, 1-7.

Cassady, J.C., \& Johnson, R.E., (2002). Cognitive Test Anxiety and Academic Performance. Contemporary Educational Psychology, 27, 270-295. doi:10.1006/ceps.2001.1094

Chapell, M.S. Blanding, Z.B. Silverstein, M.E. Takahashi, M. Newman, B. Gubi, A. et al. (2005). Test anxiety and academic performance in undergraduate and graduate students. Journal of Educational Psychology, 97, 268-274. http://dx.doi.org/10.1037/0022-0663.97.2.26

Chew-Graham, C.A., Rogers, A., \&Yassin, N. (2003). 'I wouldn't want it on my CV or their records': medical students' experiences of help-seeking for mental health problems. Medical Education, 37, 873-880.

Childline (2015). http://www.theguardian.com/education/2015/may/14/calls-to-childline-over-examstress-break-records

Dandeneau, S.D., Baldwin, M.R., Baccus, J.R., Sakellaropoulo, M.P., \& Pruessner, J.C. (2007). Cutting stress off at the pass: Reducing vigilance and responsiveness to social threat by manipulating attention. Journal of Personality and Social Psychology, 93, 651-666.

Driscoll, R. (2007). Westside Test Anxiety Scale Validation. Education Resources Information Center, 6pp. http://www.amtaa.org/res/svtxt.html

Elliot, A. J., \& McGregor, H. A. (2001). A 2 \# 2 achievement goal framework. Journal of Personality and Social Psychology, 80, 501e519.http://www.selfdeterminationtheory.org/SDT/ documents/ 2001_ElliotMcGregor.pdf

Ergene, T. (2003). Effective Interventions on Test Anxiety Reduction: A Meta-Analysis. School Psychology International, 24,313-328.

Fredrickson, B.L., Cohn, M.A., Coffey, K.A., Pek, J., \& Finkel, S.M. (2008). Open hearts build lives: Positive emotions, induced through loving-kindness meditation, build consequential personal resources. Journal of Personality and Social Psychology, 95, 1045-1062.

Gilbert, P., Clarke, M., Hempel, S., Miles, J.N.V., \& Irons, C. (2004). Criticizing and reassuring oneself: An exploration of forms, styles and reasons in female students. British Journal of Clinical Psychology, 43, 31-50. DOI: 10.1348/014466504772812959.

Gilbert, P., McEwan, K., Matos, M., \& Rivis, A. (2011). Fears of compassion: Development of three selfreport measures. Psychology and Psychotherapy: Theory, Research and Practice, 84, 239-255.

Hedman, E., Ljótsson, B., Kaldo, V., Hesser, H., El Alaoui, S., Kraepelin, M., ..., Lindefors, N. (2014). Effectiveness of internet-based cognitive behaviour therapy for depression in routine psychiatric care. Journal of Affective Disorders, 155, 49-58.

Hedman, E., Andersson, G., Ljótsson, B., Andersson, E., Rück, C., Mörtberg, E. \& Lindefors, N. (2011). Internet-based cognitive behavior therapy vs. cognitive behavioral group therapy for social anxiety disorder: A randomized controlled non-inferiority trial. PLoS One, 6, e18001.

Hembree, R. (1988). Correlates, causes, effects and treatment of test anxiety. Review of Educational Research, 58, 47-77. 
Huntley, C.D., Young, B., Jha, V., Fisher, P.L. (2016). The efficacy of interventions for test anxiety in university students: A protocol for a systematic review and meta-analysis. International Journal of Educational Research, 77, 92-98.doi.org/10.1016/j.jier.2016.03.001

Kelly A.C., Zuroff, D.C., Foa, C.L \& Gilbert, P. (2010). Who benefits from self-compassion self-regulation? Astudy of smoking cessation Journal of Social and Clinical Psychology, 29, 727-755.

Klatt, M., Harpster, K., Browne, E., White, S.\& Case-Smith, J. (2013). Feasibility and preliminary outcomes for Move-into-Learning: An arts-based mindfulness classroom intervention. Journal of Positive Psychology, 8, 233-241.

Kuyken, W., Weare, K., Ukoumunne, O.C., Vicary, R., Motton, N., Burnett, R., ..., Huppert, F. (2013). Effectiveness of the Mindfulness in Schools Programme: non-randomised controlled feasibility study. The British Journal of Psychiatry, 203, 126-131. DOI: 10.1192/bjp.bp.113.126649.

Larson, H.A., El Ramahi, M.K., Conn, S.R., Estes, L.A., \& Ghibellini, A.B. (2010). Reducing test anxiety among third grade students through the implementation of relaxation techniques. Journal of School Counseling, 8, 1-19.

Leary, M.R., Tate, E.B., Adams, C.E., Batts Allen, A., \& Hancock, J., (2007). Self-Compassion and Reactions to Unpleasant Self-Relevant Events: The Implications of Treating Oneself Kindly. Journal of Personality and Social Psychology, 92, 887-904. DOI: 10.1037/0022-3514.92.5.887.

Lovibond, S.H. \& Lovibond, P.F. (1995). Manual for the Depression Anxiety Stress Scales (2nd ed.). Sidney Psychology Foundation.

McEwan, K. \& Gilbert, P. (2016). A pilot feasibility study exploring the practising of compassionate imagery exercises in a nonclinical population. Psychology and Psychotherapy. 89, 239-243. doi: 10.1111/papt.12078.

Midgley, C., Maehr, M. L., Hruda, L. Z., Anderman, E., Anderman, L., Freeman, K. E., ..., Urdan, T., (2000). Manual for the Patterns of Adaptive Learning Scales. Ann Arbor, MI: University of Michigan. Available from http://www.umich.edu/ pals/PALS\%202000_V13Word97.pdf Last accessed 31/08/17

Musiat, P., Conrod, P., Treasure, J., Tylee, A., Williams, C., Schmidt, U. (2014). Targeted Prevention of Common Mental Health Disorders in University Students: randomised Controlled Trial of a Transdiagnostic Trait-Focused Web-Based Intervention. PLOS ONE, 4, 1-10. doi:10.1371/ journal.pone.0093621

Neff, K. D. (2003a). Self-compassion: An alternative conceptualization of a healthy attitude toward oneself. Self and Identity, 2, 85-101.

Neff, K. D. (2003b). The development and validation of a scale to measure self-compassion. Self and Identity, 2, 223-250.

Neff, K.D., Hsieh, Y.P., Dejitterat, K. (2005). Self-compassion, Achievement Goals, and Coping with Academic Failure. Self and Identity, 4, 263-287, DOI: 10.1080/13576500444000317

Paul, G., Elam, B., \& Verhulst, S. J. (2007). A longitudinal study of students' perceptions of using deep breathing meditation to reduce testing stresses. Teaching \& Learning in Medicine, 19, 287-292.

Putwain, D.W.\& Daly, A.L. (2013). Do clusters of test anxiety and academic buoyancy differentially predictacademic performance? Learning and Individual Differences, 27,157-162.http://dx.doi.org/ 10.1016/j.lindif.2013.07.010Last accessed 31/08/17

Reiss, N., Warnecke, I., Tolgou, T., Krampen, D., Luka-Krasgrill, U. \& Rohrmann, S. (2016). Effects of cognitive behavioral therapy with relaxation vs. imagery rescripting on test anxiety: A randomized controlled trial. Journal of Affective Disorders, 208, 483-489. DOI: http://dx.doi.org/ 10.1016/j.jad.2016.10.039Last accessed 31/08/1

Richardson, M., McEwan, K., Maratos, F. \& Sheffield, D. (2016). Joy and Calm: How an Evolutionary Functional Model of Affect Regulation Informs Positive Emotions in Nature. Evolutionary Psychological Science, 2, 308-320

Royal College of Psychiatrists (2011). The Mental Health of Students in Higher Education. London: Royal College of Psychiatrists.

Shapira, L. B. \& Mongrain M. (2010). The benefits of self-compassion and optimism exercises for individuals vulnerable to depression. Journal of Positive Psychology, 5, 377-389.

Sharifiniya, G.\& Golmohammadi, Z. (2014). Impact of Mindfulness-based Stress Reduction Training on Third Grade High School Female Students' Mental Health and Educational Achievement. Current Research Journal of Biological Sciences, 6, 13-19. ISSN: 2041-076X, e-ISSN: 2041-0778. 
Shepherd, D.A. \& Cardon, M.S. (2009). Negative Emotional Reactions to Project Failure and the SelfCompassion to Learn from the Experience. Journal of Management Studies, 46, 923-949. doi: 10.1111/j.1467-6486.2009.00821.

Smeets, E., Neff, K., Alberts, H., \& Peters, M. (2014). Meeting suffering with kindness: Effects of a selfcompassion intervention for female college students. Journal of Clinical Psychology, 1-5 DOI: $10.1002 / j c l p .22076 .1$

Welford, M. \& Langmead, K. (2015). Compassion-based initiatives in educational settings. Educational \& Child Psychology, 32, 71-80.

Williams, J. G., Stark, S. K., \& Foster, E. E. (2008). Start today or the very last day? The relationships among self-compassion, motivation, and procrastination. American Journal of Psychological Research, $4,37-44$.

Wisner, B. L. (2014). An exploratory study of mindfulness meditation for alternative school students: Perceived benefits for improving school climate and student functioning. Mindfulness, 5, 626-638. DOI $10.1007 / \mathrm{s} 12671-013-0215-9$.

Wood Brooks, A. (2013). Get Excited: Reappraising Pre-Performance Anxiety as Excitement. Journal of Experimental Psychology: General. 143, 1-15. DOI: 10.1037/a0035325 